\title{
Development and Validation of Ultra Violet Spectrophotometric and Reversed-Phase High Performance Liquid Chromatography Techniques for Simultaneous Estimation of Brinzolamide and Brimonidine Tartrate in Ophthalmic Suspension Formulation
}

\author{
GUNASEKAR MANOHARAN* and MOHAMMED AL-BRATTY \\ College of Pharmacy, Pharmaceutical Chemistry Department, \\ Jazan University, Alrawda Dist, Jazan, 82726, Saudi Arabia \\ ${ }^{\star}$ Corresponding author E-mail: Shekarphd@yahoo.com
}

http://dx.doi.org/10.13005/ojc/320236

(Received: February 15, 2016; Accepted: March 29, 2016)

\begin{abstract}
A sensitive and fast UV spectrophotometric technique and feasible reverse phase liquid chromatographic method for the analysis of Brinzolamide and Brimonidine tartrate in ophthalmic formulation has been developed. Linearity ranges for both methods were $5-25 \mathrm{ig} / \mathrm{ml}$ and $1-5 \mathrm{ig} / \mathrm{ml}$ for brinzolamide and brimonidine tartrate respectively. The absorption maxima were observed at 232 and $257 \mathrm{~nm}$ for Brinzolamide and Brimonidine. The UV, ophthalmic formulation assay shows percentage purity ranging from 98.90 to $101.01 \%$ for Brinzolamide and 98.20 to $100.80 \%$ for Brimonidine. The mean percentage purity is $99.82 \%$ and $99.80 \%$ for Brinzolamide and Brimonidine respectively. The chromatographic retention time for Brinzolamide and Brimonidine was found to be 5.9 and 8.4 minutes respectively. The tailing factor was 0.808 and 0.860 for Brinzolamide and Brimonidine tartrate respectively. The method was validated according to the $\mathrm{ICH}$ guidelines and the method was found to be applicable for determination of Brinzolamide and Brimonidine tartrate from combined ophthalmic form.
\end{abstract}

Keywords: Brinzolamide (BRZ), Brimonidine (BRT), HPLC and UV.

\section{INTRODUCTION}

Glaucoma is a disorders characterized by a loss of visual associated with optic nerve damage and associated with intra-ocular pressure rise. Glaucoma is categorized into two forms primary open-angle glaucoma and primary angle closure glaucoma. The drugs which used to reduce intra-ocular pressure is achieved by different types of mechanism ${ }^{1-2}$. The first choice of drug is topical beta-blocker or prostaglandin analogues. It is necessary to combine these drugs or by adding with other types like sympathomimetics miotics, or carbonic anhydrase inhibitors to maintain ocular pressure ${ }^{3}$. Brinzolamide chemically called as 4R)-4-(ethylamino)-2-(3-methoxypropyl)-1,1dioxo-2H,3H,4H-1 $\lambda^{\beta}$-thieno[3,2-e][1,2]thiazine-6- 
sulfonamide (Figure 1a) is a carbonic anhydrase inhibitor used to the patients with open-angle glaucoma to lower hypertension by decreasing the fluid amount produced by eyes. Blindness is prevented by lowering pressure inside the eye ${ }^{1}$. Brimonidine chemically called as 5-Bromo- $\mathrm{N}-(4,5-$ dihydro-1H-imidazol-2-yl) quinoxalin-6-amine (Figure $1 b)$, which is a alpha -adrenoceptor agonist, used in the reduction of intra-ocular pressure in open- angle glaucoma or ocular hypertension. Brimonidine is also used as adjunctive therapy when intra-ocular pressure is inadequate ${ }^{4-6}$.

Literature review reveals several methods developed has been reported for Brinzolamide estimation in biological fluids and there are some methods reported by voltammetry ${ }^{7}$, spectroscopy ${ }^{8}$, HPTLC HPLC, UPLC and capillary electrophoresis ${ }^{9-11}$. Two methods were only reported for estimation of this combination first is HPTLC ${ }^{12}$ and the other is HPLC method $^{13-15}$. The latter does not fulfil all requirements of validation. Method development of simultaneous UV and HPLC estimation for this combination is our new method will fulfil all requirements of validation according to $\mathrm{ICH}$ guidelines. It should be characterized by simplicity, fast analysis, sensitivity and suitability for routine pharmaceutical analysis.

\section{MATERIALS AND METHODS}

\section{Chemicals and reagents}

The working standard of Brinzolamide and Brimonidine was purchased from Sigma, UK. The Marketed sample of Brimonidine Tartrate $0.2 \%$ and Brinzolamide 1\% ophthalmic preparation 'Simbrinza' were from Alcon Laboratories (UK) Ltd, purchased from the local Pharmacy, Jazan, KSA. Acetonitrile and Methanol HPLC grade was purchased from

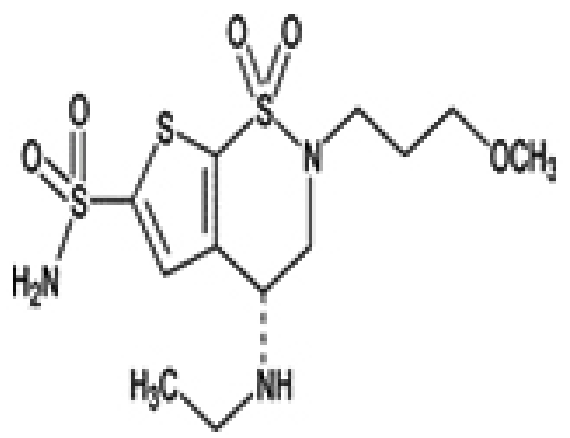

Fig. 1a: Chemical structure of Brinzolamide
Merck, Darmstadt, Germany, Triethylamine and Orthophosphoric acids purchased from Fisher Scientific (UK).

\section{Pharmaceutical preparation}

Simbrinza eye drops; Alcon Laboratories (U.K) contains (Brimonidine Tartrate $0.2 \%$ and Brinzolamide 1\%) B.NO: AMCM3111

\section{Instrumentation}

UV spectrophotometer

A double beam UV-visible spectrophotometer-Shimadzu, UV-1601 (Japan) matched with quartz cells corresponding to $1 \mathrm{~cm}$ path length.

\section{HPLC instrumentation and chromatographic condition}

HPLC system of Shimadzu LC-20 AT, with an auto sampler (SIL-20AC HT, Shimadzu, Japan) and SPD-10 detector (SPD- M20A, Japan) was used. For data recording the LC-solution software used. A Zorbax Eclipse Plus, Agilent Technology column (150mm x 4.6mm, 5ìmwas used, ) Pore size of the column $95 \AA$. For degassing mobile phase, power sonic 505 ultrasonic baths (Hwashin technology, Seoul, Korea) was used. By using oven (CTO-20AC) column was maintained at a temperature of $39^{\circ} \mathrm{C}$ and $1.0 \mathrm{ml} / \mathrm{min}$ was the flow rate. Analysis was carried over with $20 \mu$ injection volume using SPD10 detection at $260 \mathrm{~nm}$. 10 minutes was set as run time.

\section{Preparation of Standard Stock Solution for UV}

The standard stock solution of Brinzolamide and Brimonidine were prepared by dissolving separately $3 \mathrm{mg}$ of Brinzolamide and Brimonidine powder respectively in $100 \mathrm{ml} 0.1 \mathrm{M} \mathrm{HCl}$. Both

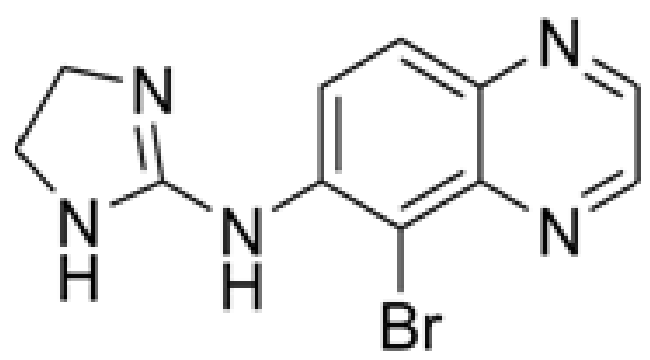

Fig. 1b: Chemical structure of Brimonidine 
Brinzolamide and Brimonidine powder freely soluble in $0.1 \mathrm{M} \mathrm{HCl}$ and does not have any interference in the absorption peaks. Accurate volumes transferred to two sets of calibrated $10 \mathrm{ml}$ flask.

\section{Development of the method}

The stock solution suitably diluted with $0.1 \mathrm{M} \mathrm{HCL}$ so as to contain $5-25 \mu \mathrm{g} / \mathrm{ml}$ and $1-5$ $\mu \mathrm{g} / \mathrm{ml}$ Brinzolamide and Brimonidine respectively. The prepared solutions were scanned in the UV region between 200nm - 400nm. The Brinzolamide exhibited $\lambda$ max at 232nm and Brimonidine exhibited $\lambda$ max at $257 \mathrm{~nm}$. The individual drug concentration present in the mixture was determined against the calibration curve in quantization mode.
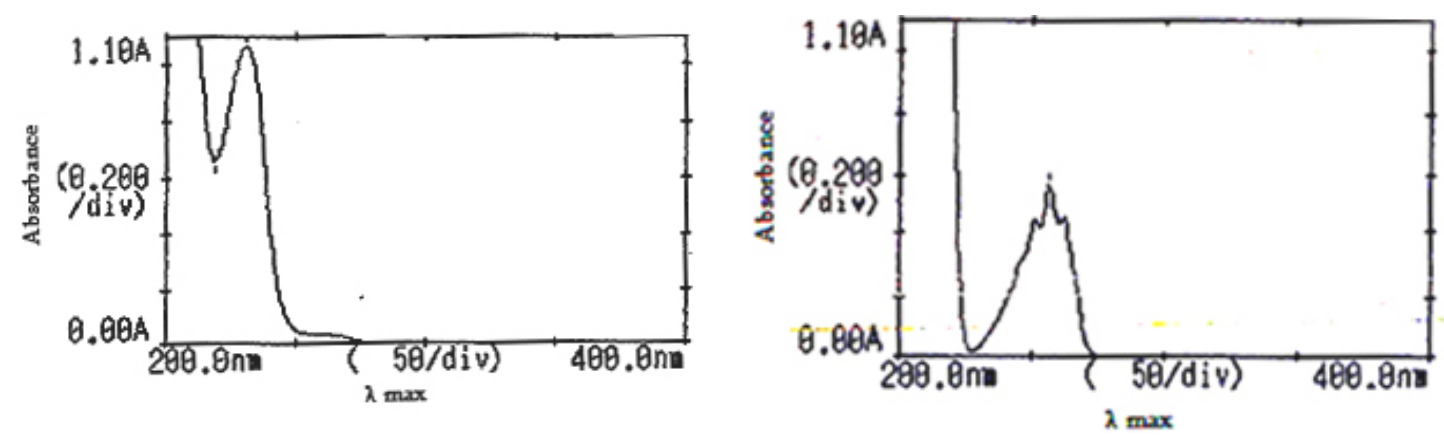

Fig. 2: UV spectrum of raw Brinzolamide and Brimonidine
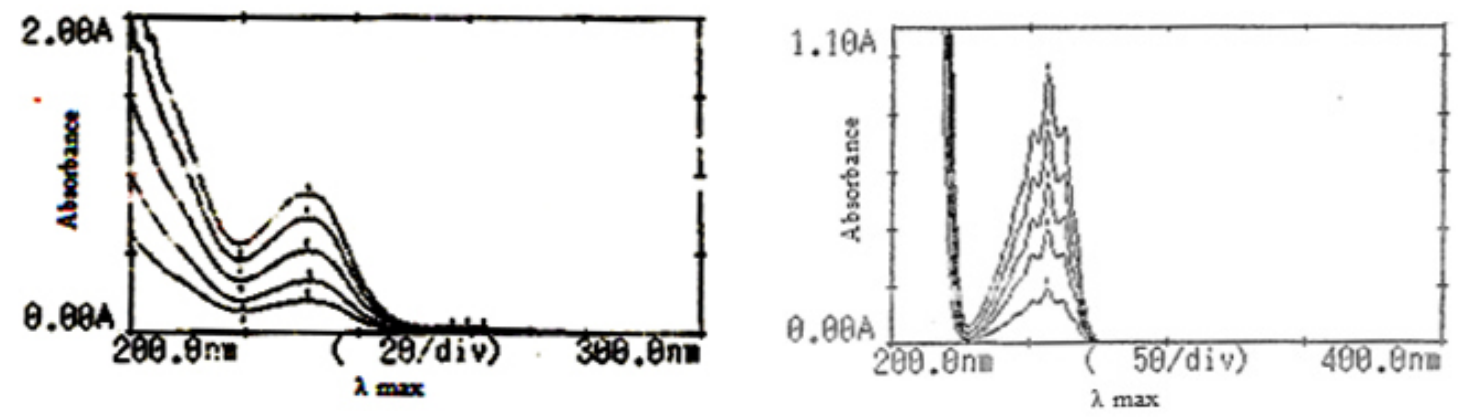

Fig. 3: UV spectrum Linearity of raw Brinzolamide and Brimonidine
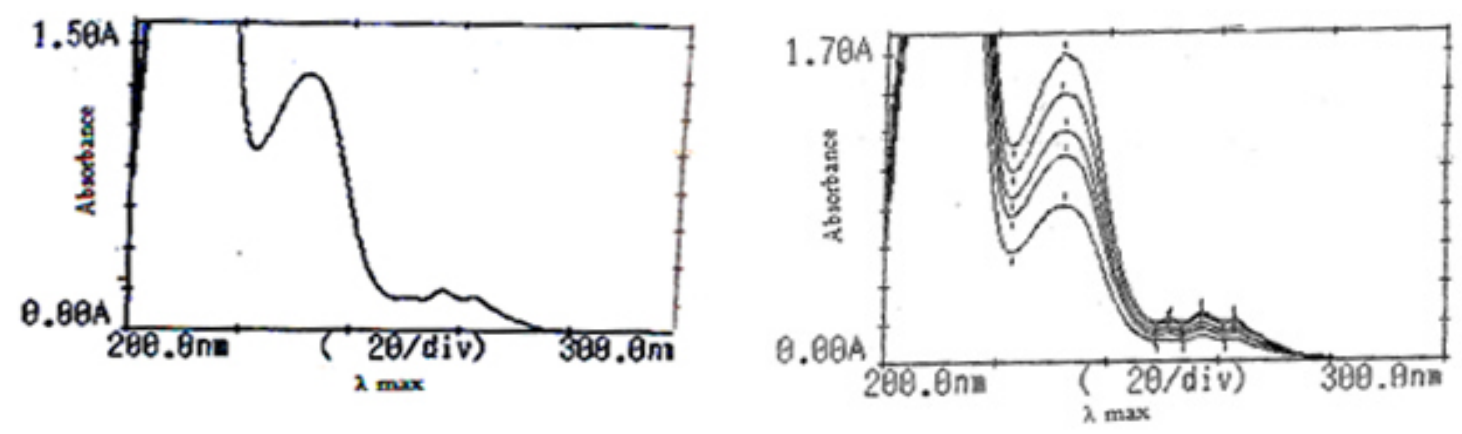

Fig. 4: Quantitative estimation of combined Brinzolamide and Brimonidine in ophthalmic formulation 
Analysis of Ophthalmic Suspension

$1 \mathrm{ml}$ suspension was taken from formulation and transferred to volumetric flask $100 \mathrm{ml}$ and diluted up to $100 \mathrm{ml}$ with $0.1 \mathrm{M} \mathrm{HCl}$, which is equivalent to 20 $\mu \mathrm{g} / \mathrm{ml}$ of Brimonidine and $100 \mathrm{ig} / \mathrm{ml}$ of Brinzolamide. From this stock, $1 \mathrm{ml}$ of solution was diluted with 0.1 $\mathrm{M} \mathrm{HCl}$ to $10 \mathrm{ml}$, which contains $2 \mathrm{ig} / \mathrm{ml}$ of Brimonidine and $10 \mathrm{ig} / \mathrm{ml}$ of Brinzolamide. The mixture kept stand

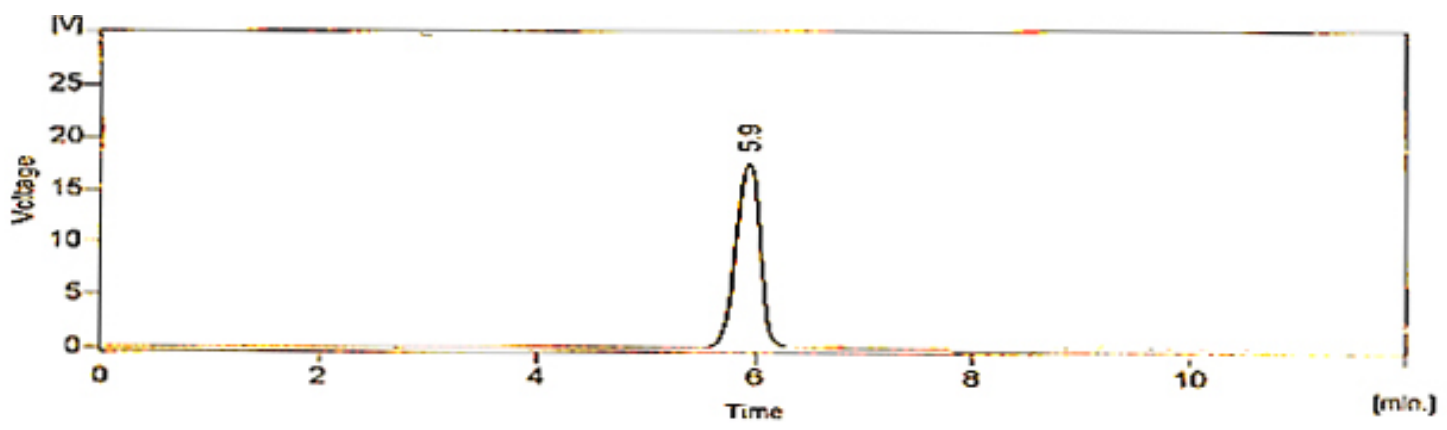

Fig. 5: A Typical Chromatogram of Brinzolamide Standard

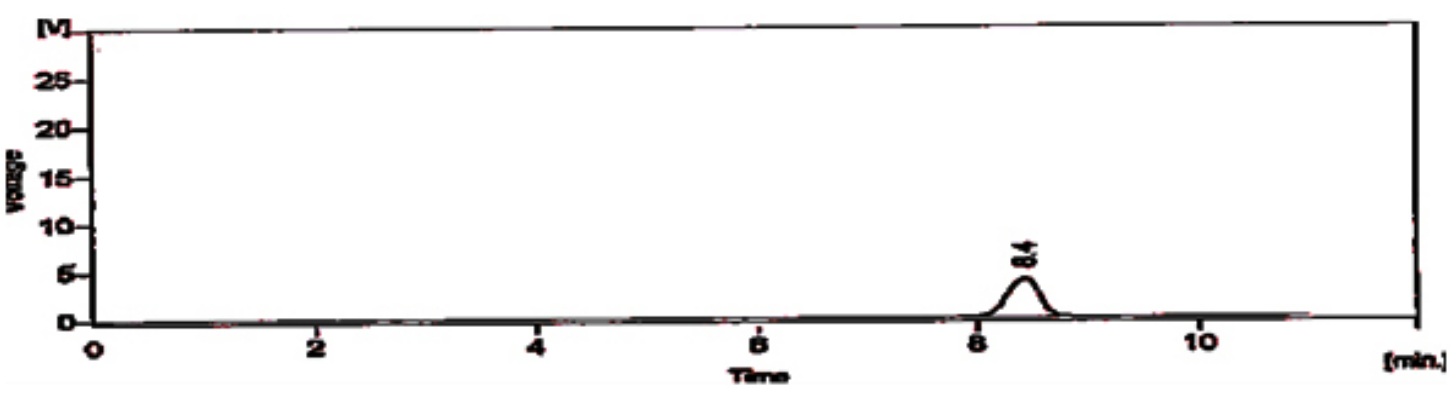

Fig. 6: A Typical Chromatogram of Brimonidine Standard

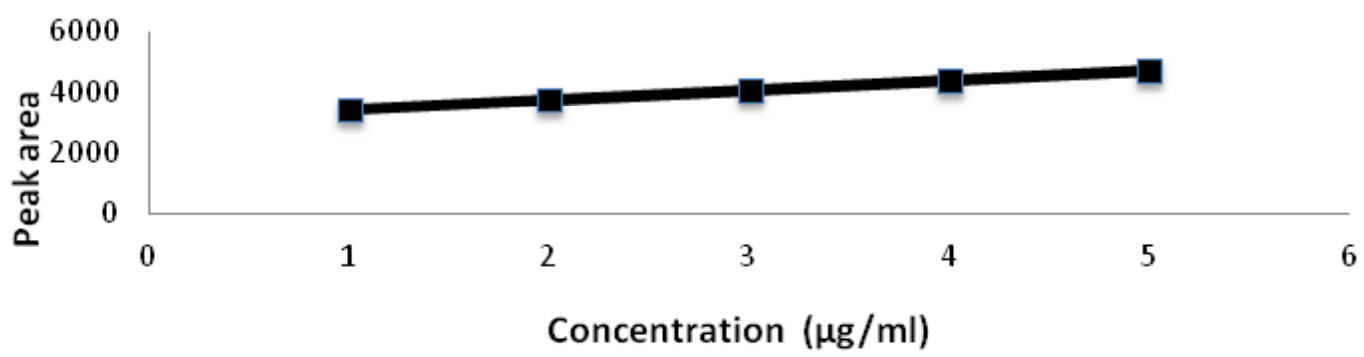

Fig. 7: Calibration graph of Brimonidine $2-5 \mu \mathrm{g} / \mathrm{ml}$ precision

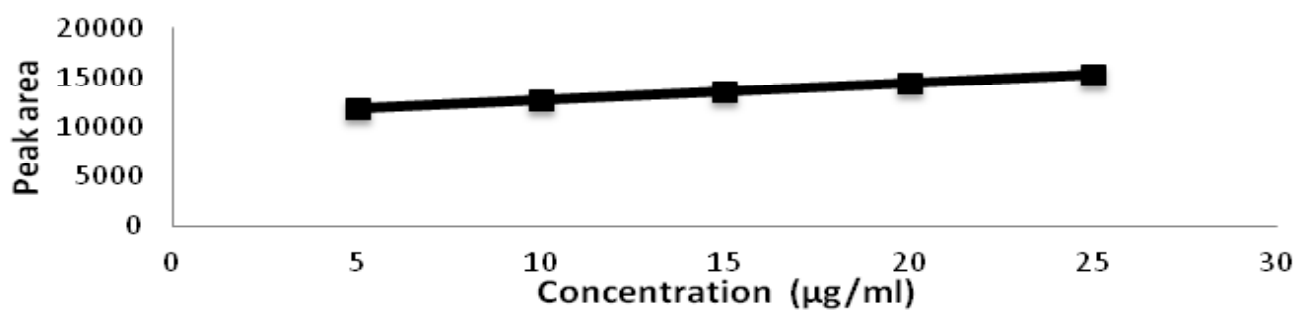

Fig. 8: Calibration graph of Brinzolamide $10-25 \mu \mathrm{g} / \mathrm{ml}$ precision 


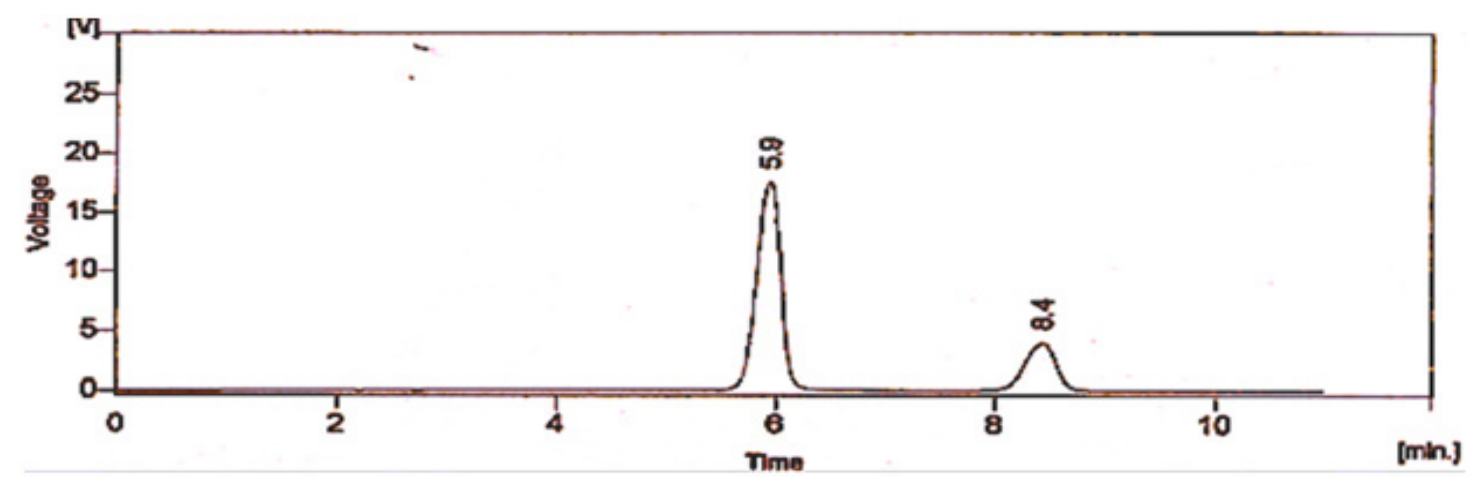

Fig. 9: Chromatogram of Brinzolamide and Brimonidine in ophthalmic formulation

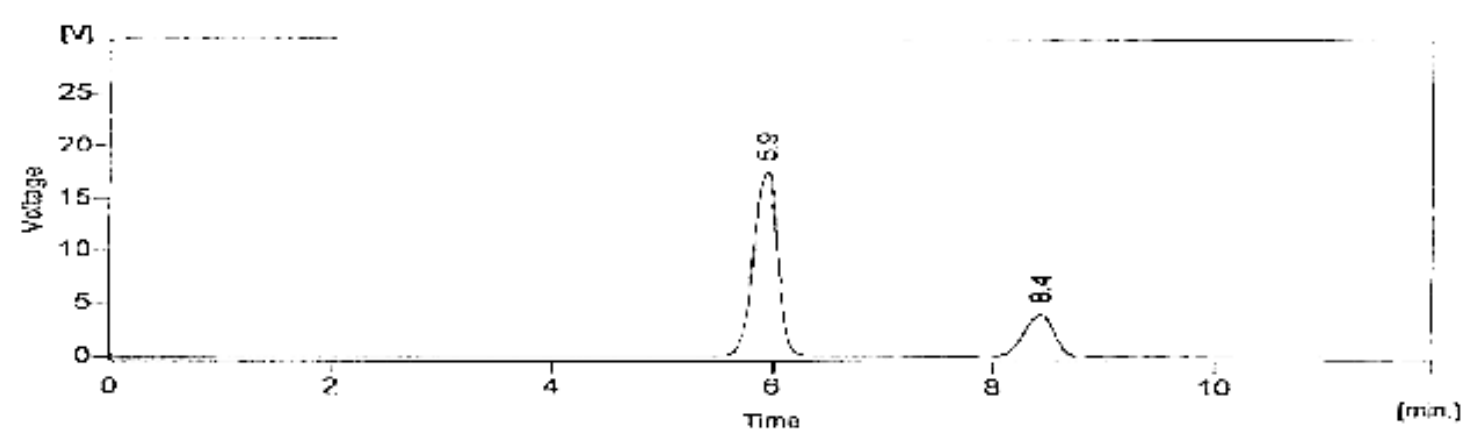

Fig. 10: Quantitative estimation (Assay) of Brinzolamide and Brimonidine in ophthalmic formulation

for $15 \mathrm{~min}$, to ensure complete solubility of the drug by intermittent sonication, and filtered through a 0.45 ìm membrane filter. The concentrations were determined by measuring the absorbance of the sample at Brimonidine $257 \mathrm{~nm}$ and Brinzolamide $232 \mathrm{~nm}$. The results were calculated against the calibration curve in quantization mode.

\section{Preparation of Standard solution for HPLC Preparation of Mobile phase}

Triethylamine phosphate buffer was prepared using $4.0 \mathrm{ml}$ of triethylamine in $1000 \mathrm{ml}$ of water by using phosphoric acid $\mathrm{pH}$ adjusted to a $5.0( \pm 0.5)$. It was filtered with $0.45 \mu$ membrane filters and degassed in an ultrasonic bath for 10 minutes. The ratio of buffer, acetonitrile and methanol was 75:20:05, v/v.

\section{Preparation of Brinzolamide Stock solution}

Accurately $5 \mathrm{mg}$ of Brinzolamide working standard was taken in $100 \mathrm{ml}$ volumetric flask and dissolved by mobile phase and diluted to $25 \mathrm{ml}$ of mobile phase and sonicated for 10 minutes and $75 \mathrm{ml}$ of mobile phase was added to the mark and cooled to room temperature. $1 \mathrm{ml}$ of standard stock solution was diluted to $10 \mathrm{ml}$ with mobile phase to obtain a concentration of $5 \mu \mathrm{g} / \mathrm{ml}$.

\section{Preparation of Brimonidine Stock solution}

Accurately $1 \mathrm{mg}$ of Brimonidine working standard was taken in $100 \mathrm{ml}$ volumetric flask and dissolved by mobile phase and diluted to $25 \mathrm{ml}$ of mobile phase and sonicated for 10 minutes and $75 \mathrm{ml}$ of mobile phase was added to the mark and cooled to room temperature. $1 \mathrm{ml}$ of standard stock solution was diluted to $10 \mathrm{ml}$ with mobile phase to obtain a concentration of $1 \mu \mathrm{g} / \mathrm{ml}$.

\section{Preparation of sample solution}

Sample bottles were shaken well before use. $10 \mathrm{ml}$ of ophthalmic suspension were taken into a dried volumetric flask $100 \mathrm{ml}$. About $50 \mathrm{ml}$ of mobile phase was added to dilute and stand for 15 minutes and diluted to mark with mobile phase. The resulting 
solution was filtered through Whatman 1 filter paper. $10 \mathrm{ml}$ of the resulting solution was diluted to $50 \mathrm{ml}$ with mobile phase and filtered by $0.45 \mu$ disc filter.

\section{Method validation}

The present method was conducted to obtain a new, sensitive and convenient method for simultaneous estimation by HPLC from ophthalmic formulation. The experimental method was validated according to the $\mathrm{ICH}$ guidelines recommendations and USP-30 for parameters such as, system suitability, accuracy, precision, linearity and specificity.

Table1: Quantitative Estimation Of Brinzolamide And Brimonidine In Ophthalmic Formulation

\begin{tabular}{lcccc}
\hline $\begin{array}{l}\text { Ophthalmic } \\
\text { sample }\end{array}$ & $\begin{array}{c}\text { Label claim } \\
(\mathbf{m g} / \mathbf{m l})\end{array}$ & $\begin{array}{c}\text { Amount } \\
\text { present }\end{array}$ & $\begin{array}{c}\text { Percentage Label } \\
\text { claim }\end{array}$ & $\begin{array}{c}\text { Percentage } \\
\text { deviation }\end{array}$ \\
\hline Brinzolamide & 10 & 9.96 & 99.20 & -0.80 \\
Brimonidine & 2 & 2.21 & 100.19 & +0.19 \\
\hline
\end{tabular}

${ }^{*}$ Each value is a mean of six readings

Table 2: UV Statistical Data

\begin{tabular}{|c|c|c|c|c|}
\hline $\begin{array}{l}\text { Ophthalmic } \\
\text { sample }\end{array}$ & $\begin{array}{l}\text { Standard } \\
\text { deviation } \\
\text { (S.D) }\end{array}$ & $\begin{array}{c}\text { Relative } \\
\text { Standard } \\
\text { deviation (RSD) }\end{array}$ & $\begin{array}{c}\text { Relative Standard } \\
\text { deviation \% RSD }\end{array}$ & $\begin{array}{c}\text { Standard Error } \\
\text { of mean (S.E) }\end{array}$ \\
\hline Brinzolamide & 0.006519 & 0.00627 & 0.627 & 0.0797 \\
\hline Brimonidine & 0.0010 & 0.001048 & 0.1048 & 0.1311 \\
\hline
\end{tabular}

* Each value is a mean of six readings

Table 3: Results Of UV Limit Of Detection (LOD) \& Limit Of Quantification LOQ

\begin{tabular}{lcc}
\hline Parameters & Brinzolamide & Brimonidine \\
\hline LOD $(\mathrm{ig} / \mathrm{ml})$ & 0.51 & 0.41 \\
LOQ $(\mathrm{ig} / \mathrm{ml})$ & 1.57 & 1.21 \\
\hline
\end{tabular}

Table 4: HPLC Linearity Data For Brimonidine

\begin{tabular}{lcc}
\hline SNo & $\begin{array}{c}\text { Concentration } \\
(\mathbf{m g} / \mathbf{m l})\end{array}$ & Peak area \\
\hline 1 & 1 & 3436.94 \\
2 & 2 & 3760.64 \\
3 & 3 & 4090.95 \\
4 & 4 & 4427.75 \\
5 & 5 & 4759.29 \\
\hline
\end{tabular}

\section{System suitability}

System suitability parameters like resolution, retention time, tailing factor and column theoretical plates was performed by injecting six replicates of standards and two replicates of sample preparation at a $100 \%$ level to cross verify the accuracy and precision of the chromatographic system.

Table 5: HPLC Linearity Data For Brinzolamide

\begin{tabular}{ccc}
\hline SNo & $\begin{array}{c}\text { Concentration } \\
(\mathbf{m g} / \mathbf{m l})\end{array}$ & $\begin{array}{c}\text { Peak } \\
\text { area }\end{array}$ \\
\hline 1 & 5 & 11903.78 \\
2 & 10 & 12763.24 \\
3 & 15 & 13628.45 \\
4 & 20 & 14493.95 \\
5 & 25 & 15358.19 \\
\hline
\end{tabular}




\section{Linearity}

The linearity of chromatographic method was established by plotting a graph to concentration vs peak area of Brinzolamide and Brimonidine standard and determining the correlation coefficients (R2) of the two compounds. For the linearity studies of Brinzolamide and Brimonidine the specific range was determined at $5-25 \mu \mathrm{g} / \mathrm{ml}$ and $1-5 \mu \mathrm{g} / \mathrm{ml}$ for Brinzolamide and Brimonidine tartrate respectively were injected into the HPLC system. For 60 minutes column was equilibrated with the mobile phase before injection of the solutions.

\section{Accuracy}

The method accuracy was determined by recovery experiments. The recovery was performed by adding Brinzolamide and Brimonidine working standards to placebo (excipients mixture) in the range of test concentration $(60 \%, 80 \%$ and $100 \%)$ and expressed as percent (\%) recovered. Three samples were prepared for each recovery level. The recovery statistical results are

\section{Precision}

The intraday and interday precision of the analyzed method was determined by analyzing the sample responses 4 repeats on the same day and 4 different days of a week for 4 different concentrations of standard solutions of Brinzolamide and Brimonidine. $10-25 \mu \mathrm{g} / \mathrm{ml}$ and $2-5 \mu \mathrm{g} / \mathrm{ml}$ for brinzolamide and brimonidine tartrate respectively, and results are represented in terms of $\%$ RSD.

\section{Specificity}

The analytical method specificity is to measure the compound accurately in presence of interferences like excipients, degradants and matrix components. The UV spectrum and HPLC of standard mixture and formulation shows specificity of method. The UV spectrophotometric and HPLC method is able to access the analyte in presence of excipients.

\section{Statistical Parameters}

The results of assay obtained are subjected to the following statistical analysis, standard

Table 6: Results Of Statistical Parameters

\begin{tabular}{llcc}
\hline SNo & Parameters & Brinzolamide & Brimonidine \\
\hline 1 & Standard deviation (SD) & 4.353 & 13.933 \\
2 & Relative standard deviation (RSD) & 0.00574 & 0.0101 \\
3 & $\%$ RSD & 0.574 & 1.011 \\
4 & Standard error (SE) & 0.02347 & 0.0836 \\
5 & Correlation Coefficient $(r)$ & 0.9983 & 0.9996 \\
6 & Slope $(a)$ & 33.1181 & 86.395 \\
7 & Intercept (b) & 1503.26 & 11037.67 \\
8 & Regression equation & $\mathrm{Y}=33.1181$ & $\mathrm{Y}=86.395$ \\
& $\mathrm{Y}=(\mathrm{aX}+\mathrm{b})$ & $\mathrm{X}+1503.26$ & $\mathrm{X}+11037.67$ \\
\hline
\end{tabular}

Table 7: Results Of System Suitability Parameters

\begin{tabular}{llcc}
\hline SNo & Parameters & Brinzolamide & Brimonidine \\
\hline 1 & Theoretical plates & 8948 & 8303 \\
2 & Tailing factor & 0.808 & 0.860 \\
3 & Resolution factor & 8.33 & 8.33 \\
4 & Retention time & 5.9 & 8.4 \\
5 & Calibration range or & $1-5$ & $5-25$ \\
& Linear dynamic range & & \\
\hline
\end{tabular}


deviation, relative standard deviation, coefficient of variation and standard error.

\section{RESULT AND DISCUSSION}

The UV spectrum of Brinzolamide and Brimonidine are showed in figure 2. The maxima absorption was observed at 232 and $257 \mathrm{~nm}$ for Brinzolamide and Brimonidine. Brimonidine attached to chomophoric molecule, increase both its wave length and intensity of absorption maximum. Increase in conjugation, increase absorbance of light to higher I, bathochromic shift with hyperchromic effects of Brimonidine are showed in figure 2.

The linearity of calibration curve of Brinzolamide and Brimonidine shows that obeyance of Beer's law was confirmed, which are represented in figure 3. Brinzolamide linearity concentration range of $5-25 \mu \mathrm{g} / \mathrm{ml}$ and Brimonidine linearity range of $1-5 \mu \mathrm{g} / \mathrm{ml}$. The overlying spectra for the linearity of Brinzolamide and Brimonidine and spectrum of sample formulation are presented in

Table 8: Results Of Limit Of Detection (LOD) \& Limit Of Quantification LOQ

\begin{tabular}{lcc}
\hline Parameters & Brinzolamide & Brimonidine \\
\hline LOD (ng/ml) & 0.430 & 0.530 \\
LOQ (ng/ml) & 1.310 & 1.610 \\
\hline
\end{tabular}

figure 4. The concentration of Brinzolamide $15 \mathrm{ig} / \mathrm{ml}$ and Brimonidine $3 \mathrm{ig} / \mathrm{ml}$ was taken for quantitative estimation.

The ophthalmic formulation shows percentage purity value ranging from $98.60-100.20 \%$ for Brinzolamide and $99.98-100.16 \%$ for Brimonidine. The $\%$ deviation was found to lie between $-1.4-+0.2$ for Brinzolamide and $-0.1-+0.2$ for Brimonidine. The relative standard deviation values are found to be below $2 \%$ indicating the methodology precision and low standard error values show the method accuracy. The quantitative estimation of Brinzolamide and Brimonidine in ophthalmic formulation is shown in table 1. The statistical data is given in table 2 . The limit of detection and limit of quantification for Brinzolamide and Brimonidine were calculated and values are given in table in table 3.

The chromatogram of Brinzolamide and Brimonidine are presented in figure 5 and 6 . Wavelength was selected by scanning all standard drugs over a wide range of wavelength 200$400 \mathrm{~nm}$. Both the components show reasonably good response at $260 \mathrm{~nm}$. Linearity was evaluated by plotting peak area as a functional of analyte concentration for both Brinzolamide and Brimonidine. The graphical representation was given in figure 7 and 8; data is presented in table 4 and 5.

The specific range was determined from linearity studies, for both drugs and found to be

Table 9: Quantitative Estimation (Assay) of Data of Brinzolamide and Brimonidine From Ophthalmic Formulation

\begin{tabular}{|c|c|c|c|c|c|c|c|}
\hline $\begin{array}{l}\text { S. } \\
\text { No }\end{array}$ & Drug & $\begin{array}{l}\text { Label } \\
\text { claim } \\
\text { (mg/ml) }\end{array}$ & $\begin{array}{l}\text { Amount } \\
\text { found }\end{array}$ & $\begin{array}{c}\text { Mean } \\
\text { amount }\end{array}$ & $\begin{array}{c}\text { Percentage } \\
\text { purity }\end{array}$ & $\begin{array}{c}\text { Mean } \\
\text { percentage }\end{array}$ & $\begin{array}{c}\% \\
\text { Deviation }\end{array}$ \\
\hline & & & 9.97 & & 99.40 & & -0.6 \\
\hline & & & 9.91 & & 98.22 & & -1.8 \\
\hline \multirow[t]{5}{*}{1} & Brinzolamide & 10 & 10.02 & 9.95 & 100.44 & 99.80 & -0.4 \\
\hline & & & 10.04 & & 100.80 & & +0.8 \\
\hline & & & 10.01 & & 100.20 & & +0.2 \\
\hline & & & 1.94 & & 98.90 & & -1.1 \\
\hline & & & 1.96 & & 99.20 & & -0.8 \\
\hline \multirow[t]{3}{*}{2} & Brimonidine & 2 & 2.05 & 1.95 & 101.01 & 99.82 & +1.1 \\
\hline & & & 2.02 & & 100.40 & & +0.4 \\
\hline & & & 1.98 & & 99.62 & & -0.4 \\
\hline
\end{tabular}


1-5 $\mathrm{mg} / \mathrm{ml}$ for Brimonidine and $5-25 \mathrm{mg} / \mu \mathrm{l}$ for Brinzolamide. The data was analyzed by linear regression least square fit method. The slop, intercept, correlation coefficient and regression equation were also determined and the data are presented in table 6 .

The suitability parameters of the system like resolution, tailing factor, retention time and theoretical plates for the developed RP-HPLC method are presented in figure 9; the data are presented in table 7.

The chromatographic retention time for Brinzolamide and Brimonidine was found to be 5.9 and 8.4 minutes respectively. This is well within the specific limits of $10-15$ minutes. The high resolution value of 8.33 Brimonidine indicates complete separation of the drugs. The tailing factor was found to be 0.808 and 0.860 for Brinzolamide and Brimonidine respectively. The peaks are symmetrical and theoretical plates for Brinzolamide and Brimonidine were 8948 and 8308 respectively which shows the column efficient performance. The limit of detection and limit of quantification for Brinzolamide and Brimonidine are presented in table 8. The quantitative estimation of Brinzolamide and Brimonidine ophthalmic formulation was carried out by RP-HPLC method using Triethylamine phosphate buffer, acetonitrile and methanol was 75:20:05, v/v using $\mathrm{C} 18$ column as the stationary phase. The quantitative estimation of the suspension formulation is presented in table 9 and graphically presented in figure 10 .

The ophthalmic formulation assay shows percentage purity ranging from 98.90 to $101.01 \%$ for Brinzolamide and 98.20 to $100.80 \%$ for Brimonidine. The mean percentage purity is $99.82 \%$ and $99.80 \%$ for Brinzolamide and Brimonidine respectively. The percentage deviation was found to be -1.1 to $+1.1 \%$ and -1.8 to +0.8 for Brinzolamide and Brimonidine respectively. The RSD values are below $2 \%$ indicating the method precision and the accuracy of the method shown by the low standard error values. This shows a good index of accuracy and reproducibility of the developed method. All the parameters including flow rate, detection wavelength sensitivity was maintained constant.

\section{CONCLUSION}

The proposed and developed UV and RPHPLC method is precise, accurate, and sensitive. The method is rapid, reproducible, and economical and does not have any interference due to the excipients in the pharmaceutical preparations.

\section{ACKNOWLEDGEMENT}

The authors are thankful and acknowledge Jazan University for financial support and required facilities to carry out this research work through a scientific research grant.

\section{REFERENCES}

1. BMJ Group. British national formulary 62 . ( $1^{\text {st }}$ edn), Pharmaceutical Press, London. 2011.

2. Narendra, A.; Deepika, D.; Annapurna, M.M. E-J Chem. 2012, 9, 1327-1331

3. Gandhi, L.R.; Dewani, A.P.; Bakal, R.L.; Shiradkar, M.R.; Chande, A.V. Int. J. Pharm. 20113 (7), 21-26

4. Naeem, R.S.; Muhammad, A.; Ullah Khanand, I.I.M. Quim. Nova. 2011, 1 (6) 200-209

5. Fahim, N.K.; Beheshti, H.R.; Feizy, J.; Janati, S.S.F. GIDA dergisi. 2012, 37, 127-132

6. Bhatta, R.S.; Chandasana, H.; Rathi, C.;
Kumar, D.; Chhonker, Y.S.; Jain, G.K. J Pharm Biomed Anal. 2011, 54, 1096-1100

7. Alberts, P.; Stander, M.A.; Villiers, A.D. South African Journal for Enology and Viticulture. 2011, 32, 51-59

8. Nagori, B.P.; Maru, A.; Muysuni, P.; Gupta, S. J Chem Pharm Res. 2011, 3, 866-874

9. Wanare, R.S.; Kabra, A.O.; Deshmukh, A.; Aher, N. Int J Compreh Pharm. 2012, 3, 1-4

10. Rele, R.V.; Mhatre, V.V.; Parab, J.M.; Warkar, C.B. J Chem Pharm Res. 2011, 3,138-144.

11. Sharma, N.; Rao, S.S.; Reddy, A.M. J Chromatogr Sci. 2012, 50, 745- 755 
12. Mehta, J.; Patel, V.; Kshatri, N.; Vyas, N. Anal. Methods. 2010, 2, 1737-1744

13. Shokraneh, F.; Dabirsiaghi, A.; Adib, N. Orient J. Chem. 2012, 28(1), 237-241
14. Jain, P.S.; Khatal, R.N.; Jivani, H.N.; Surana, S.J. J Chromatograph Separat Techniq. 2011, 2, 113-117

15. Phogat, A.; Kumar, M.S.; Mahadevan, N. Int J Rec Adv Pharm Res. 2011, 3, 31-36. 